\title{
Hydrothermal synthesis and characterization of a new layered compound $\mathrm{Li}_{2} \mathrm{VGeO}_{5}$ 光
}

\author{
Mehtap Emirdag-Eanes ${ }^{\mathrm{a}, *}$, Joseph W. Kolis ${ }^{\mathrm{b}}$ \\ a Department of Chemistry, Izmir Institute of Technology, Izmir 35430, Turkey \\ ${ }^{\mathrm{b}}$ Hunter Research Laboratory, Department of Chemistry, Clemson University, Clemson, SC 29634-0973, USA
}

Received 12 August 2003; received in revised form 3 September 2003; accepted 3 September 2003

\begin{abstract}
The new compound $\mathrm{Li}_{2} \mathrm{VGeO}_{5}$ with a layered structure has been synthesized at $580{ }^{\circ} \mathrm{C}$ via the hydrothermal method. The compound crystallizes in the space group $P 4 / n$ of the tetragonal system with two formula units in a cell of dimensions $a=6.5187(9) \AA, c=4.5092(9) \AA$ $(T=298 \mathrm{~K}), V=191.61(5) \AA^{3}$. The structure is composed of layers made of repeating $\left[\left(\mathrm{VO}_{5}\right)\left(\mathrm{GeO}_{4}\right)\right]^{1-}$ units. Li ${ }^{+}$ions reside between the layers. The magnetic susceptibility data show an antiferromagnetic coupling below $5 \mathrm{~K}$ with $C=0.47 \mathrm{emu} \mathrm{K} \mathrm{mol}^{-1}$, and $\theta=-13 \mathrm{~K}$ with $\mu_{\text {eff }}=1.89 \mu_{\mathrm{B}}$ for each $\mathrm{Li}_{2} \mathrm{VGeO}_{5}$ unit.
\end{abstract}

(C) 2003 Elsevier B.V. All rights reserved.

Keywords: Hydrothermal method; Crystal structure; Antiferromagnetic coupling

\section{Introduction}

Layered compounds are of great interest due to their potential applications as ion exchange ionic conductors, batteries and catalysts $[1,2]$. Synthetic efforts have been directed towards the exchange or insertion of a metal cation into the channels or layers of such compounds. Lithium is the most commonly used cation because of its small size, high mobility and large charge density. Vanadyl(IV) phosphates, especially (VO) ${ }_{2} \mathrm{P}_{2} \mathrm{O}_{7}$, have been the subject of recent studies due to their efficiency as catalysts in the production of maleic anhydride from butane and air [3-5]. $\mathrm{V}(\mathrm{IV}) \mathrm{O}_{5}$ pyramids in (VO) ${ }_{2} \mathrm{P}_{2} \mathrm{O}_{7}$ link with diphosphate groups to form a dense-layered structure. Discovery of this compound has encouraged further exploration which has led to the synthesis of several new exotic vanadium compounds. Tetravalent vanadium has a $\mathrm{d}^{1}$ electronic configuration and occurs in a five (square pyramidal) or a six (octahedral) coordination. The $\mathrm{d}^{1}$ electron is located in one of the nonbonding orbitals

\footnotetext{
Supplementary data associated with this article can be found, in the online version, at doi:10.1016/j.jallcom.2003.09.027.

* Corresponding author. Present address: Izmir Yuksek Teknoloji Enstitusu, Fen Fakultesi, Kimya Bolumu, Gulbahce koyu, Urla 35430, Izmir, Turkey. Tel.: +90-232-498-7564; fax: +90-232-498-7509.

E-mail address: mehtapemirdag@iyte.edu.tr (M. Emirdag-Eanes).
}

$\left(3 \mathrm{~d}_{x y}\right)$ and is responsible for the interesting magnetic and optical properties of layered vanadium compounds [6]. In this paper, we describe the hydrothermal synthesis of a new layered vanadium(IV) germanate which has a layered structure with $\mathrm{Li}^{+}$ions located between the layers.

\section{Experimental}

\subsection{Syntheses}

Single crystals of title compounds were synthesized from $0.015 \mathrm{~g}\left(1 \times 10^{-4} \mathrm{~mol}\right) \mathrm{V}_{2} \mathrm{O}_{3}$ and $0.042 \mathrm{~g}\left(4 \times 10^{-4} \mathrm{~mol}\right)$ $\mathrm{GeO}_{2}$. The starting materials were placed into silver tubes $(0.25 \mathrm{~cm}$ o.d.) with $0.4 \mathrm{ml}$ of an aqueous $0.5 \mathrm{M}$ solution $\mathrm{LiOH}$. The tubes were then welded shut. Welded tubes were placed into Tuttle "cold sealed" autoclave and heated at $580^{\circ} \mathrm{C}$ for 3 days. After the heating process, the autoclave was cooled down under flowing air. The product was washed with water and dark maroon crystals of $\mathrm{Li}_{2} \mathrm{VGeO}_{5}$ were obtained in $40 \%$ yield along with $\mathrm{LiVGe}_{2} \mathrm{O}_{6}$. Based on the vanadium(IV) oxidation state in $\mathrm{Li}_{2} \mathrm{VGeO}_{5}$, another reaction was tried to get a better yield of this compound. A mixture of $\mathrm{V}_{2} \mathrm{O}_{3}\left(0.075 \mathrm{~g}, 5 \times 10^{-5} \mathrm{~mol}\right)$ and $\mathrm{V}_{2} \mathrm{O}_{5}(0.090 \mathrm{~g}$, $5 \times 10^{-5} \mathrm{~mol}$ ) were used as starting materials along with the same amount of $\mathrm{GeO}_{2}$ and $\mathrm{LiOH}$, and the reaction mixtures 
was heated at $583{ }^{\circ} \mathrm{C}$ for 3 days. An approximately $80 \%$ yield of $\mathrm{Li}_{2} \mathrm{VGeO}_{5}$ was obtained from the second reaction.

\subsection{Crystallography}

A crystal of $\mathrm{Li}_{2} \mathrm{VGeO}_{5}$, with the approximate dimensions of $0.1 \mathrm{~mm} \times 0.05 \mathrm{~mm} \times 0.03 \mathrm{~mm}$ was mounted on a four-circle Rigaku AFC8 diffractometer equipped with a Mercury CCD area detector. Data were collected at room temperature $(\sim 300 \mathrm{~K})$ using graphite monochromated Mo $\mathrm{K} \alpha(\lambda=0.71073 \AA)$ radiation. The crystal-to-detector distance was approximately $30 \mathrm{~mm}$. A total of 240 frames were recorded as an $\omega$ scans of $1^{\circ}$ with an X-ray exposure time of $30 \mathrm{~s}$. Tetragonal $P 4 / n, z=2, a=6.5187(9) \AA$, $c=4.5092(9) \AA, V=191.61(5) \AA^{3}, D_{\text {cal }}=3.768 \mathrm{~g} \mathrm{~cm}^{-3}$, $\mu(\mathrm{Mo} \mathrm{K} \alpha)=10.174 \mathrm{~mm}^{-1}$. An empirical absorption correction was applied using a REQABA routine in CrystalClear software package. The transmission factors ranged from 0.630 to 1.000 . The data were merged and averaged in the Laue group $4 / m$, yielding an internal agreement factor of $R_{\mathrm{m}}=0.001$. A total of 256 reflections were used for structure elucidation. Of these, 255 were independent and 242 with $I>2 \sigma(I)$ were used in the refinement. The structure was solved by direct methods with the program SHELXS and refined full-matrix least-squares techniques with the program SHELXL in the SHELXTL suite [7].

\section{Results and discussion}

The compound was originally isolated as a by-product of our effort to prepare the spin-Peierls V(III) compound $\mathrm{LiVGe}_{2} \mathrm{O}_{6}[8,9]$. It was subsequently prepared with good yield by the following designed synthesis.

$\mathrm{V}_{2} \mathrm{O}_{3}+\mathrm{V}_{2} \mathrm{O}_{5}+2 \mathrm{GeO}_{2} \underset{580^{\circ} \mathrm{C}}{\stackrel{\mathrm{LiOH}(\mathrm{aq})}{\longrightarrow}} \mathrm{Li}_{2} \mathrm{VGeO}_{5}$

The structure of $\mathrm{Li}_{2} \mathrm{VGeO}_{5}$ was determined by single crystal X-ray diffraction. The title compound has been obtained as maroon polyhedra and has a layered structure with square pyramidal vanadyl groups connected by tetrahedral germanates. The unit cell view of this compound is shown in Fig. 1. In Fig. 2, corner sharing $\mathrm{VO}_{5}$ and $\mathrm{GeO}_{4}$ units can be seen. The layers, $\mathrm{VO}_{5} / \mathrm{GeO}_{4}$, lie along the $a b$ plane, and the lithium atoms reside between the layers. There are two crystallographically inequivalent oxygen atoms. Vanadium has four equal bonds to $\mathrm{O} 2$ atoms in the square plane with a bond distance of 1.959(3) $\AA$. In addition, there is a fifth short bond to the $\mathrm{O} 1$ atom of $1.643(7) \AA$, typical of a $\mathrm{V}=\mathrm{O}$ group. The $\mathrm{O} 1-\mathrm{V}-\mathrm{O} 1$ angle in the square plane ranges from $84.40(5)^{\circ}$ to $143.59(16)^{\circ}$ and the $\mathrm{O} 1-\mathrm{V}-\mathrm{O} 2$ angle is $108.21(8)^{\circ}$. Schindler et al. found that vanadyl bond distances range from 1.48 to $1.66 \AA$ with a maximum at $1.59 \AA$, while equatorial $\mathrm{V}-\mathrm{O}$ bonds are in the range of $1.8-2.12 \AA$ with a maximum at $1.97 \AA$ [10]. The angles between the vanadyl bond and the four equatorial bonds are

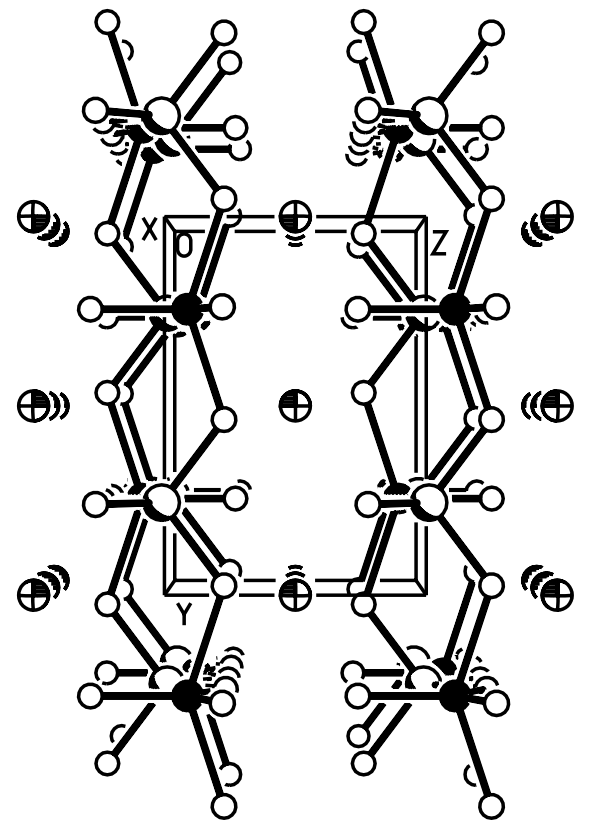

Fig. 1. A projection of the unit cell as viewed down the $a$-axis. $\mathrm{Li}_{2} \mathrm{VGeO}_{5}$, where $\mathrm{Ge}$ atoms are shaded circles, $\mathrm{V}$ atoms are solid circles, $\mathrm{O}$ atoms are open circles and $\mathrm{Li}$ is full thermal ellipsoids with $70 \%$ probability. Selected bond distances and angles are as follows: $\mathrm{V} 1=\mathrm{O} 2=1.637(4)$ $\AA ; \mathrm{V} 1-\mathrm{O} 1=1.959(2) \times 4 \AA ; \mathrm{Ge} 1-\mathrm{O} 1=1.748(2) \times 4 \AA . \mathrm{O} 1-\mathrm{V} 1-$ $\mathrm{O} 2=108.17(5)^{\circ} \times 4 ; \mathrm{O} 1-\mathrm{V} 1-\mathrm{O} 1=84.42(3)^{\circ} \times 4 ; \mathrm{O} 1-\mathrm{V} 1-\mathrm{O} 1=$ $143.66(10)^{\circ} \times 4 . \mathrm{O} 1-\mathrm{Ge} 1-\mathrm{O} 1=111.11(6)^{\circ} \times 4 ; \mathrm{O} 1-\mathrm{Ge} 1-\mathrm{O} 1=$ $106.25(11)^{\circ} \times 2$.

in the range $100-110^{\circ}$. Our results for $\mathrm{V}-\mathrm{O}$ bond distances and angles are in complete agreement with their study. The germanium atom has four equal $\mathrm{Ge}-\mathrm{O}$ bonds forming a tetrahedron $(1.750(3) \AA)$. The lithium atoms between the layers have four short bonds to the $\mathrm{O} 2$ atom and four longer bonds to the $\mathrm{O} 1$ atom with bond distances of 2.039(2) and 2.533(2) , respectively.

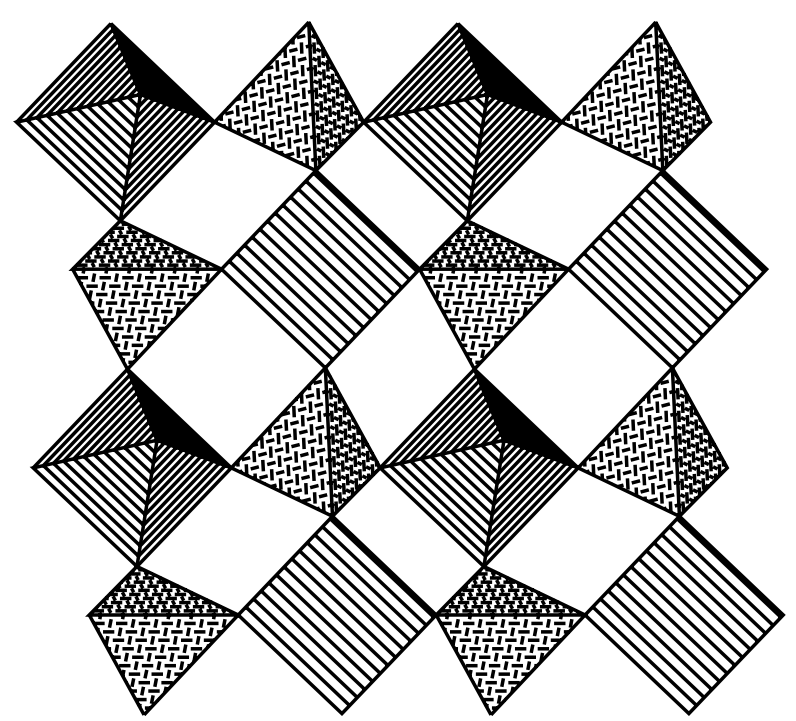

Fig. 2. The $\mathrm{VO}_{5} / \mathrm{GeO}_{4}$ layer, $\mathrm{VO}_{5}$ are shown as lined polyhedra, and $\mathrm{GeO}_{4}$ tetrahedra are herringbone polyhedra. 


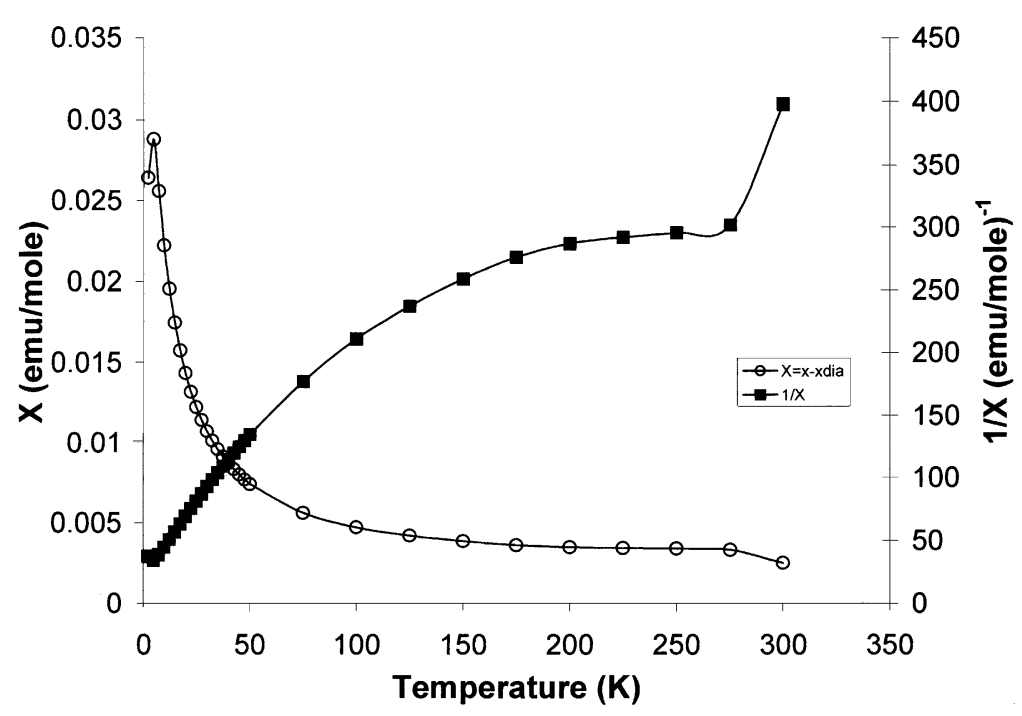

Fig. 3. Plot of magnetic susceptibility (solid squares) and reciprocal susceptibility (open circles) as a function of temperature for $\mathrm{Li}_{2} \mathrm{VGeO}_{5}$.

$\mathrm{Li}_{2} \mathrm{VGeO}_{5}$ has a structure very similar to $\alpha-\mathrm{VOPO}_{4}$ $[11,12]$. The layered units are isostructural except that the two interlayer $\mathrm{Li}^{+}$ions charge compensate for the $\mathrm{V}(\mathrm{IV})$ in our title compound. The layered compound vanadyl phosphate is a good host for intercalation reactions and it is isostructural with a number of other compounds containing pentavalent metals including, $\mathrm{NbOPO}_{4}$ [13], $\mathrm{TaOPO}_{4}$ [14], $\mathrm{VOMoO}_{4}$ [15], $\mathrm{MoOPO}_{4}$ [16] and $\alpha-\mathrm{VOSO}_{4}$ [17]. In $\alpha-\mathrm{VOPO}_{4}$, six oxygen atoms surround the vanadium to form a very distorted octahedron with one long bond $(2.85 \AA)$ and one short bond $(1.58 \AA)$ along the $c$-axis. Without this long bond, the coordination of vanadium can be considered a square pyramid. In contrast, in the title compound the $\mathrm{Li}$ atom separates the layers by over $4 \AA$, thus making the vanadium an ideal square pyramid. This very weak bond in $\alpha-\mathrm{VOPO}_{4}$ can be replaced with other ligands leading to its extensive intercalation chemistry. As many as two water molecules can fit between the layers [18]. It should be noted that there is a known lithium vanadyl phosphate, $\beta-\mathrm{LiVOPO}_{4}$ [19], but it has a structure very different from $\alpha-\mathrm{VOPO}_{4}[20]$.

The bond valence sums for crystallographically unique atoms in the title compound were calculated in order to help determine their approximate oxidation states. The vanadium has a +4 charge as expected from its crystal structure and all the other atoms have values close to their expected oxidation states. $^{1}$

Fig. 3 shows the temperature dependence of the magnetic susceptibility and reciprocal magnetic susceptibility for $\mathrm{Li}_{2} \mathrm{VGeO}_{5}$. $\mathrm{Li}_{2} \mathrm{VGeO}_{5}$ does not display Curie-Weiss behavior over the temperature range considered here. A Néel point, $T_{N}$, for the transition from paramagnetic to antiferromagnetic behavior was observed at $4.62 \mathrm{~K}$.

\footnotetext{
${ }^{1}$ Bond valence sums for $\mathrm{Li}_{2} \mathrm{VGeO}_{5}: \mathrm{V}(1)=3.96(5), \mathrm{Ge}(2)=$ 3.98(4), $\mathrm{Li}(3)=0.91(6), \mathrm{O}(1)=1.67(3), \mathrm{O}(2)=1.83(2)$.
}

The IR absorption spectra of $\mathrm{Li}_{2} \mathrm{VGeO}_{5}$ were consistent with the X-ray structure. There are three bands centered at $810,820,755 \mathrm{~cm}^{-1}$ which could be associated with the $\mathrm{GeO}_{4}$ group. The absence of a broad band above $3000 \mathrm{~cm}^{-1}$ suggests that the compound does not contain the $\mathrm{OH}^{-}$ion. A stretch observed at $960 \mathrm{~cm}^{-1}$ is characteristic of $\mathrm{V}=\mathrm{O}$ stretching typically seen at $985 \pm 50 \mathrm{~cm}^{-1}$ [21]. The diffuse reflectance spectrum of $\mathrm{Li}_{2} \mathrm{VGeO}_{5}$ at room temperature reveals the presence of an electronic transition centered at $575 \mathrm{~nm}$, as expected by its dark maroon color. The optical band gap was approximately $1 \mathrm{eV}(1000 \mathrm{~nm})$.

In summary, we have successfully synthesized hydrothermally well formed single crystals. $\mathrm{Li}_{2} \mathrm{VGeO}_{5}$ has a very interesting layered structure built of $\mathrm{V}(\mathrm{IV}) \mathrm{O}_{5}$ square pyramids and $\mathrm{GeO}_{4}$ tetrahedra with $\mathrm{Li}^{+}$ions between the layers. We feel that with the careful choice of base mineralizers and transition metals, a wide variety of new transition metal germanates will be discovered using hydrothermal techniques.

\section{Acknowledgements}

We are indebted to the NSF for support of this work (CHE-9714408). We also acknowledge the NSF (CHE-9808165) for purchase of the CCD diffractometer.

Supporting information available: X-ray crystallographic files in CIF format for $\mathrm{Li}_{2} \mathrm{VGeO}_{5}$.

\section{References}

[1] D.W. Murphy, S.A. Sushire, S.M. Zahurak, in: Chemical Physics of Interaction, NATO ASI Series, Series B: Physics, vol. 172, Plenum, New York, 1987, p. 173.

[2] A. Clearfield, Chem. Rev. 88 (1988) 125

[3] C.C. Torardi, J.C. Calabrese, Inorg. Chem. 23 (1984) 1308. 
[4] J.W. Johnson, D.C. Johnston, A.J. Jacobson, J.F. Brudy, J. Am. Chem. Soc. 106 (1984) 8123.

[5] M.E. Leonowicz, J.W. Johnson, J.F. Brody, H.F. Shannon Jr., J.M. Newsam, J. Solid State Chem. 56 (1985) 370.

[6] Y. Udea, Chem. Mater. 10 (1998) 2653.

[7] G.M. Sheldrick, "SHELXTL-PLUS," Version 6.10, Bruker AXS, Siemens Analytical X-Ray Instruments, Inc., Madison, WI.

[8] P. Millet, F. Mila, F.-C. Zhang, M. Mambrini, A.B. Van Oosten, V.A. Pashchenko, A. Sulpice, A. Stepanov, Phys. Rev. Lett. 83 (1999) 4176.

[9] M. Emirdag-Eanes, J.W. Kolis, unpublished work.

[10] M. Schindler, F.C. Hawthorne, W.H. Baur, Chem. Mater. 12 (2000) 1248.
[11] B. Jordan, C. Calvo, Can. J. Chem. 51 (1973) 2621.

[12] R. Gopal, C. Calvo, J. Solid State Chem. 5 (1972) 432.

[13] J.M. Longo, P. Kierkegaard, Acta Chem. Scand. 20 (1966) 72.

[14] J.M. Pierce, J.A. Kafalas, Mater. Res. Bull. 6 (1971) 1157.

[15] H.A. Eick, L. Kihlborg, Acta Chem. Scand. 20 (1966) 722.

[16] P. Kierkegaard, M. Westerlund, Acta Chem. Scand. 18 (1964) 2217.

[17] J.M. Longo, R.J. Arnott, J. Solid State Chem. 1 (1970) 394.

[18] J.W. Johnson, A.J. Jacobson, J.F. Brody, S.M. Rich, Inorg. Chem. 21 (1982) 3820.

[19] K.H. Lii, C.H. Li, J. Solid State Chem. 95 (1991) 352.

[20] R. Gopal, C. Calvo, J. Solid State Chem. 5 (1972) 432.

[21] W.W. Wendlandt, H.G. Hecht, in: Reflectance Spectroscopy, Interscience, New York, 1966. 